\title{
PERSPECTIVE OPEN \\ Towards Quality by Design and process analytical technology for enhanced nutrient recovery from wastewaters
}

\author{
Céline Vaneeckhaute ${ }^{1}$
}

Recovering nutrients from wastewater as sustainable bio-based products provides a key solution to major environmental problems. Classical technology development approaches for resource recovery largely ignore the real-world variability in raw waste materials, which currently hinders the successful implementation of recovery strategies. A major challenge is to create a consistent and environmentally friendly supply of high-quality end-products that can compete with fossil-derived products currently on the market. This paper suggests the use of a Quality by Design approach as adapted from the pharmaceutical industry to ensure a high standard of quality consistency. Key elements of this approach involve mathematical models and integrated design-control strategies that support the production of high-quality marketable end-products from variable input waste and wastewater streams. Further research in terms of cost evaluation and optimisation of such approach for resource recovery applications is needed. A regulatory framework for Process Analytical Technology implementation in the field is also suggested.

npj Clean Water (2019)2:14; https://doi.org/10.1038/s41545-019-0038-x

\section{WHY NUTRIENT RECOVERY?}

Nutrients, especially nitrogen $(\mathrm{N})$, phosphorus $(\mathrm{P})$ and potassium (K), are vital for food security and required for socio-economic stability. ${ }^{1,2}$ However, several minerals, such as $\mathrm{P}$ and $\mathrm{K}$, that are being extracted through mining, are becoming scarce at a rapid pace. $^{1}$ The quality of the remaining natural resources is deteriorating and geopolitical moves make nutrient scarcity an imminent threat to food security, as recently observed in global fluctuating prices, socio-economic unrest and distribution disruptions. $^{1}$ Moreover, significant amounts of (fossil) energy are currently used to convert non-reactive atmospheric nitrogen $\left(\mathrm{N}_{2}\right)$ into reactive nitrogen $\left(\mathrm{NH}_{4}\right)$ compounds for synthetic fertiliser production. ${ }^{1}$ Meanwhile, the demand for nutrients continues to increase in line with the continuously growing world population, while a large proportion is being wasted causing major environmental, health and economic problems. ${ }^{1}$ It is thus time for a new global effort to reduce nutrient losses and to improve nutrient use efficiency across all sectors, thereby providing the foundation for a greener economy with secured food and energy production and less environmental pollution.,

To attack the nutrient problem, over the last decade, innovative research efforts have been set up on the development and implementation of strategies and technologies for recovery of nutrients from bio-waste and wastewater streams. ${ }^{3,4}$ As such, due to strict water quality regulatory measures worldwide, municipal and industrial wastewater treatment plants are slowly transforming into water resource recovery facilities (WRRFs), ${ }^{3}$ whereas the appearance of waste biorefineries is on the rise. ${ }^{4}$ Moreover, due to climate change mitigation objectives and associated renewable energy, biofuel production and greenhouse gas reduction targets, municipal and private sectors are forced to valorise organic waste materials such as sewage sludge and food waste. ${ }^{5}$ On the other hand, the agricultural sector must adopt sustainable strategies for food production, using, e.g., "smart» fertilisers such as formulated controlled release granular products. ${ }^{6}$ Specific regulatory measures driving nutrient recovery innovations involve, for example, the inclusion of phosphate rock on the European list of Critical Raw Materials, ${ }^{7}$ the revision of the European fertiliser regulation to regulate and stimulate the use of recovered mineral fertiliser products, ${ }^{7}$ the Ontario (CA) Waste Free Act implemented in 2016 comprising circular economy and nutrient recovery objectives, ${ }^{5}$ and the recently proposed NutrientSmart program by the United States Environmental Protection Agency (USEPA) to encourage and recognise the adoption of enhanced nutrient management practices by WRRFs and their communities. ${ }^{8}$

Hence, the recovery of nutrients from waste and wastewater streams as sustainable bio-based fertiliser products provides a promising solution to meet the above regulatory objectives.

\section{NEED FOR A PARADIGM SHIFT}

Over the past decade, several industrial technologies for nutrient recovery from bio-waste and wastewaters have been proposed and implemented at pilot or full scale. Key technologies include anaerobic digestion for biogas recovery and simultaneous nutrient mineralisation, ${ }^{9}$ (subsequent) $\mathrm{P}$ precipitation/crystallisation for struvite $\left(\mathrm{MgNH}_{4} \mathrm{PO}_{4}\right)$ recovery ${ }^{10}$ and $\mathrm{N}$ stripping and subsequent absorption for ammonium sulfate recovery. ${ }^{11}$ However, important challenges remain in improving the operational performance of these technologies, decreasing the economic costs and environmental impact, and recovering the nutrients as marketable products with added value, e.g., for the agricultural or chemical sector. ${ }^{3,10,12}$

A major challenge in nutrient recovery from raw waste and wastewaters is to create a consistent, sustainable and environmentally friendly supply of high-quality end-products that can

\footnotetext{
${ }^{1}$ BioEngine, Research team on green process engineering and biorefineries, Laboratory on Quality by Design (QbD) in bio-products engineering, Chemical Engineering Department, Université Laval, 1065, avenue de la Médecine, Québec, QC G1V 0A6, Canada

Correspondence: Céline Vaneeckhaute (celine.vaneeckhaute@gch.ulaval.ca)
}

Received: 11 March 2019 Accepted: 30 May 2019

Published online: 15 July 2019 
compete with (fossil-derived) products currently on the market. $2,3,10,12$ Indeed, in order to provide marketable end-products, important product properties (i.e., specifications such as particle size, $\mathrm{pH}$, nutrient content) must continuously be kept within an appropriate limit, range or distribution to ensure reliable and consistent product quality to end-users. ${ }^{12}$ This is especially challenging for resource recovery facilities since the input raw materials (i.e., waste and wastewater streams) to these facilities are highly variable in time and space. ${ }^{3,12}$ Concretely, products with narrow specification margins must be recovered from raw materials to which no specifications can be imposed. ${ }^{3,10,12}$ Also the final effluent quality must meet specific standards for reuse or discharge. ${ }^{12}$ On top of that, in a competitive market scenario, the installations must be operated as flexibly as possible in order to adapt satisfactorily to changes in product specifications, market demand, different feed conditions and raw material quality variations. $^{12}$

Nevertheless, classical development approaches for emerging nutrient recovery technologies target single process reproducibility only (with/without post-process quality inspection) and largely ignore real-world variability in raw waste materials. ${ }^{12,13}$ Energy efficiency and chemical dosing are discussed from a steady-state perspective for single unit processes, while in fact the main opportunities lie in dealing with the inherent dynamics of the combination of unit processes in treatment trains. ${ }^{14,15}$ Also, process and control system design are usually performed sequentially, again without consideration of interactions, leading to needless and excessive overdesign, poor resilience and low flexibility. ${ }^{15-17}$ Clearly, these strategies are not attractive from an economic, efficiency, sustainability and end-user viewpoint. ${ }^{14-17}$

Hence, in order to promote the establishment of a circular nutrient economy, there is urgent need for a paradigm shift from the classical technology development approaches above to sustainable integrated end-user focused strategies, supported by a reliable, competitive and repeatable quality assurance framework. ${ }^{2}$ An improved balance between efficiency and cost in biobased production chains is needed, while continuously assuring product quality and safety. ${ }^{2,3,10,12}$

This paper proposes a pro-active approach to bio-product development, thereby bridging the gap between industrial technology development (technology push) and demand-driven product valorisation (market pull). Concretely, the paper proposes the use of a Quality by Design (QbD) approach adapted to nutrient recovery. Such QbD approach is widely applied in the pharmaceutical sector in which a consistent end-product quality is critical, ${ }^{18}$ but has never been adapted to and applied for nutrient recovery from waste and wastewater, although clearly relevant.

\section{QUALITY BY DESIGN: WHAT IS IT?}

The Quality by Design (QbD) concept was first outlined by the world renowned quality expert Joseph M. Juran in the book Juran on Quality by Design. ${ }^{19}$ According to Juran, designing for quality and innovation is key to achieve breakthroughs in new products, services, and processes, and hence a prerequisite to achieve business success. Juran believed that quality could be planned, and that most quality crises and problems relate to the way in which quality was planned. ${ }^{19}$ As such, the US Food and Drug Administration (FDA) has identified product planning using $\mathrm{QbD}$ principles as best practice in the pharmaceutical industry. ${ }^{20}$

Conventional $\mathrm{QbD}$ as applied in the pharmaceutical industry implies a systematic approach to drug development focused on end-user needs. Key to the approach is the identification and understanding of product critical quality attributes (CQAs) and critical process parameters (CPPs). ${ }^{20-22}$ An example of a CQA is drug particle diameter, which must be controlled within predefined limits. Other CQAs can be related to product safety, efficiency, stability and performance. ${ }^{20-22}$ An example of a CPP is the process operational temperature, which can have an influence on the CQAs. CPPs should be monitored and controlled over time with appropriate control strategies to ensure that the process continuously produces the desired product quality. ${ }^{20-22}$ The overall goal is to achieve risk management throughout the product's life cycle, as well as continuous improvement. ${ }^{20}$

Along with the implementation of $\mathrm{QbD}$, advances appeared in the field of product quality testing for product quality acceptability. With the FDA's introduction of process analytical technologies (PAT) that allow for real-time measurements, such as spectroscopic technologies, the current trend in the pharmaceutical industry is not only to monitor CPPs but also CQAs during processing. ${ }^{23}$ This allows to rapidly identify and understand the influence of changing process parameters or variable raw material characteristics on product quality. In fact, $\mathrm{QbD}$ and PAT complement each other and may together allow to abandon quality control testing of product samples for verification of product quality acceptability. ${ }^{23}$

\section{QBD FOR NUTRIENT RECOVERY: KEY CHALLENGES AND ADVANCES}

As indicated above, an important complication in the marketing of recovered products is that these new products have to compete with what is already on the market, e.g., with synthetically produced fertilisers. Hence, an important step in the proposed $\mathrm{QbD}$ approach is the upgrading of the raw recovered materials and their formulation into high-quality consistent marketable and/ or certifiable end-products in compliance with current regulations and market specifications. This step is of primary importance to take new bio-based products to commercial use and hence to stimulate the implementation of recovery strategies. ${ }^{2}$ Indeed, when recovering raw nutrient products, nutrient ratios are usually not optimal for marketing, e.g., the N/P and K/P ratios of products recovered from sewage sludge are often too low for immediate bio-fertiliser application. Through coating of such products, e.g., with recovered urea or $\mathrm{K}$ fertilisers, a tailor-made granule with improved and optimised composition can be created. ${ }^{6}$ Hence, upon development of a new process, a target product quality profile (including the identification of CQAs) should be created, taking into account not only process performance and CPPs, but also costs, product markets and regulations. As such, in view of increasingly strict environmental regulations, markets are moving towards granular or pelletised products, e.g., controlled-release fertilisers with high nutrient use efficiencies. ${ }^{6}$ Such products are safer, more environmentally friendly and efficient, as well as more cost-effective, e.g., in terms of transport costs and yields. ${ }^{6}$

Once target product quality profiles are set, the proposed QbD method is based on the assessment of product and process knowledge and understanding through dynamic data collection and advanced mathematical modelling so as to pro-actively design processes and treatment trains that allow to continuously meet the desired product quality (Fig. 1). The use of mathematical models is key to technology design, performance optimisation and troubleshooting of processes since they are both time- and cost-efficient. ${ }^{24}$ Moreover, models can fill the gap between lab/ pilot-scale experiments and commercial scale operation. ${ }^{25}$ Hence, mathematical models are an integral part of the proposed QbD approach. An important complication in the development of nutrient recovery models is that, in contrast to the traditional biological nutrient removal processes used in wastewater treatment plants, the main unit processes considered in resource recovery systems rely on changes in the physicochemical properties, e.g., ion activities, chemical redox state, degree of supersaturation, of the solution. ${ }^{26}$ In turn, these fundamental properties are determined by the underlying chemical solution speciation, which is the detailed distribution of total chemical component amounts between the ionic species physically present in the 


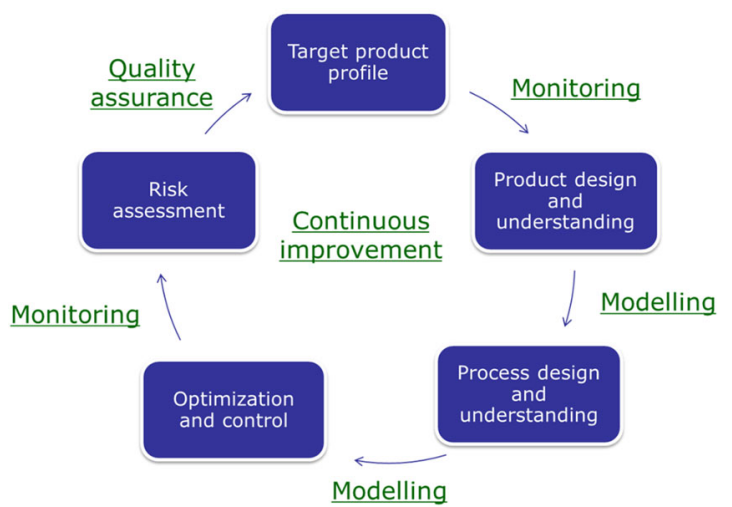

Fig. 1 Simplified overview of the proposed QbD approach for nutrient recovery

system. ${ }^{26}$ Consequently, using models to ensure consistent production of a pure and marketable product from a variable complex waste matrix is challenging.

Vaneeckhaute et al. ${ }^{27}$ recently developed a generic nutrient recovery model (NRM) library, including advanced mathematical process models for the most established nutrient recovery technologies available to date, i.e., $\mathrm{N}$ stripping/absorption, struvite precipitation/crystallisation, as well as anaerobic digestion for nutrient release. The models are based on a unique physicochemical modelling framework, combining detailed chemical solution speciation as well as biochemical and physicochemical reaction kinetics. This first available NRM library has recently been implemented in the widely applied WEST software platform (DHI) and will be made available for use by industry, municipalities and consultants worldwide. Other attempts to include physicochemical concepts in wastewater treatment process models are reported, for example, by Flores-Alsina et al., ${ }^{28}$ Lizarralde et al., ${ }^{29}$ Mbamba et al. ${ }^{30}$ and Solon. ${ }^{31}$ However, these studies focus mainly on conventional wastewater treatment processes with limited attention to the optimization of nutrient recovery treatment trains and end-product quality.

Further, the proposed QbD approach starts and ends with the end-user. Upon introduction of a new product, there's always some amount of trade-off involved. If there are multiple end-users, they may also have conflicting needs. Even the same end-user may have needs that compete with each other. Hence, global optimisation of the various process performance and product quality attributes is needed. Due to the complex and variable nature of waste materials, finding the optimal combination of unit processes in treatment trains for nutrient (and energy) recovery and the optimal operating conditions that maximise resource recovery at minimal cost and environmental impact is challenging. ${ }^{31}$ Vaneeckhaute et al. ${ }^{14}$ recently developed a novel method using the NRM models and global sensitivity analysis to set up optimal resource recovery treatment train configurations. The developed models and method may be applied as a cost-effective tool for optimisation of single unit processes, for selection of optimal unit process combinations, and for optimisation of holistic valorisation chains. The aim is to minimise overall costs, environmental and social impacts, while maximising recovered product quality and yield. Moreover, this strategy allows to efficiently identify the CPPs that mostly influence the CQAs.

Next to real-time process and product quality monitoring to improve process understanding, another goal of the $\mathrm{QbD}$ approach is to use the real-time critical information to steer or adjust the process toward its desired state based on feedback and feedforward loops. This poses an important challenge for resource recovery facilities as compared to traditional wastewater treatment plants, since the former do not only have to cope with one-sided effluent quality specifications (maximum concentrations of certain pollutants), but also with (narrow) two-sided product quality specifications (e.g., margins of certain chemical components) for marketing. Every new product and process has an associated optimal design and control strategy, while treatment train interactions must also be considered. ${ }^{31}$ To tackle these challenges, the use of model-based integrated design and control strategies, i.e., methods that implement control at the design stage, to ensure that products of desired quality are produced consistently, is proposed. Integrated design and control may lead to cost savings of up to $50 \%$ compared to sequential design and control approaches. ${ }^{17}$ However, applications are lacking in the field of resource recovery, although highly relevant in light of enduser focused bio-product manufacturing.

\section{OUTLOOK}

The proposed $\mathrm{QbD}$ approach for nutrient recovery is entirely based on stakeholder involvement. Indeed, recovered products must be developed in order to satisfy end-user desires. There is an urgent need for improved communication and knowledge transfer between industry, consultants, researchers and endusers such as farmers. Initiatives have been taken across the world to establish nutrient stakeholder platforms, such as the European Sustainable Phosphorus Platform (ESPP), the Canadian Nutrient Recovery and Reuse Platform (CNRR) and the Sustainable Phosphorus Alliance (SPA). Increased awareness of these platforms among the various stakeholders involved in bio-based production chains is needed, while funding opportunities to support such initiatives should be provided. Moreover, strategies to jointly develop and implement $\mathrm{QbD}$ approaches within these stakeholder platforms should be explored. Indeed, QbD concerns an interdisciplinary approach, involving, e.g., chemistry, physics, and engineering principles, requiring continuous improvement and innovation. Hence, close collaborations between industry, researchers and consultants should be deployed to bridge knowledge gaps for implementing QbD concepts.

Further, a regulatory framework should be outlined for PAT implementation in nutrient recovery applications. This may not only motivate the water and waste industry to improve resource recovery production processes, but can also result in significant financial benefits due to reduced product quality testing and increased revenues through marketing of qualitative bio-products.

Finally, implementing a full QbD strategy with PAT is often perceived as expensive and time-consuming for pharmaceutical companies. ${ }^{20}$ The above proposed approach for nutrient recovery is a simplified approach focussing on stakeholder needs and tackling product marketing issues. In the long term, we believe that such approach can reduce production costs through increased process knowledge and understanding, while achieving an improved product quality that is more competitive with currently produced synthetic fertilisers. Through model-based process and treatment train optimisation, higher yields can also be achieved with as few resources as possible, while through monitoring and control, resource and R\&D needs can further be reduced. Nevertheless, a detailed economic analysis of the proposed QbD implementation with PAT in a real full-scale resource recovery plant is needed and will be aspect of further research.

\section{ACKNOWLEDGEMENTS}

The author is financed by the Natural Science and Engineering Research Council of Canada (NSERC) through the award of a Discovery Grant (RGPIN-2017-04838). 


\section{ADDITIONAL INFORMATION}

Competing interests: The author declares no competing interests.

Publisher's note: Springer Nature remains neutral with regard to jurisdictional claims in published maps and institutional affiliations.

\section{REFERENCES}

1. Sutton, M. A. et al. Our Nutrient World: The challenge to produce more food and energy with less pollution, Global Overview of Nutrient Management, Centre for Ecology and Hydrology, Edinburgh on behalf of the Global Partnership on Nutrient Management and the International Nitrogen Initiative. (Centre for Ecology and Hydrology (CEH), Edinburgh, UK, 2013).

2. IISD. Nutrient Recovery and Reuse in Canada: Foundations for a national framework. (International Institute for Sustainable Development, Winnipeg, 2018).

3. IWA. State of the art compendium report on resource recovery from water. (International Water Association, London, 2015).

4. de Jong, E. \& Jungmeier, G. Biorefinery Concepts in Comparison to Petrochemical Refineries, In: Industrial biorefineries and white biotechnology. (eds Pandey, A., Höfer, R., Taherzadeh, M., Nampoothiri, K. M., Larroche, C. Ch. 1.) (Elsevier, Oxford, 2015).

5. Murray, H. G. R. Bill 151, Waste-Free Ontario Act. (Ministry of the Environment and Climate Change, Ontario, 2016)

6. Pulat, M. \& Yoltay, N. Smart fertilizers: preparation and characterization of gelatinbased hydrogels for controlled release of MAP and AN fertilizers. Agrochimica 60, 249-261 (2016).

7. Buckwell, A. \& Nadau, E. Nutrient recovery and reuse (NRR) in Europe agriculture: $A$ review of the issues, opportunities, and actions. (The Rise Foundation, Brussels, 2016).

8. USEPA. NutrientSmart (NSmart), United States Enviromental Protection Agency, https://www.epa.gov/nutrient-policy-data/nutrientsmart-nsmart (2019).

9. Mao, C., Feng, Y., Wang, X. \& Ren, G. Review on research achievements of biogas from anaerobic digestion. Renew. Sust. Energ. Rev. 45, 540-555 (2015).

10. Rahman, M. M. et al. Production of slow release crystal fertilizer from wastewaters through struvite crystallization: a review. Arab. J. Chem. 7, 139-155 (2014).

11. Bonmati, A. \& Flotats, X. Air stripping of ammonia from pig slurry: characterisation and feasibility as a pre- or post-treatment to mesophilic anaerobic digestion. Waste Manag. 23, 261-272 (2003).

12. Vaneeckhaute, $C$. et al. Nutrient recovery from digestate: systematic technology review and product classification. Waste Biomass Valor. 8, 21-40 (2017).

13. Vega, P., de Rocco, L. R., Revollar, S. \& Francisco, M. Integrated design and control of chemical processes-Part I: revision and classification. Comput. Chem. Eng. 71, 602-617 (2014).

14. Vaneeckhaute, C. et al. Optimizing the configuration of integrated nutrient and energy recovery treatment trains: a new application of global sensitivity analysis to the generic nutrient recovery model (NRM) library. Bioresour. Technol. 269, 375-383 (2018).

15. Regmi, P. \& Corominas, L. Process control strategies for dynamic efficiency modelling: From unit to whole-plant. In Proc. 5th IWA/WEF Wastewater Treatment Modelling Seminar 2016 (WWTMod2016). (International Water Association (IWA) and Water Environment Federation (WEF), Annecy, 2016).

16. Stephanopoulos, G. \& Reklaitis, G. V. Process systems engineering: from Solvay to modern bio- and nanotechnology: a history of development, successes and prospects for the future. Chem. Eng. Sci. 66, 4272-4306 (2011).
17. Sharifzadeh, M. Integration of process design and control: a review. Chem. Eng. Res. Des. 91, 2515-2549 (2013).

18. Drug Regulations. Quality by design: The new quality paradigm. (Drug Regulations, Mumbai, IN, 2015). https://www.slideshare.net/shettyuc/qbd-for-beginnersintroduction-13953395.

19. Juran, J. M. Juran on Quality by design: The new steps for planning quality into goods and services, 538. (Free Press, New York, 1992).

20. $\mathrm{Yu}, \mathrm{L}$. X. et al. Understanding pharmaceutical quality by design. AAPS J. 16, 771-783 (2014).

21. Torres, M. Challenges in implementing quality by design: An industry perspective. Bioprocess International, https://bioprocessintl.com/analytical/downstreamdevelopment/challenges-in-implementing-quality-by-design-an-industryperspective/ (2015).

22. Sangshetti, J. N., Deshpande, M., Zaheer, Z., Shinde, D. B. \& Arote, R. Quality by design approach: regulatory need. Arab. J. Chem. 10, 3412-3425 (2017).

23. FDA. Guidance for industry: PAT-A framework for innovative pharmaceutical development, manufacturing and quality assurance. (US Food and Drug Administration, Rockville, 2004).

24. Rieger, L. Guidelines for using activated sludge models, IWA Scientific and Technical Report 22. (IWA Publishing, International Water Association, London, 2012).

25. Yu, L., Zhao, Q., Jiang, A. \& Chen, S. Analysis and optimization of ammonia stripping using multi-fluid model. Water Sci. Technol. 63, 1143-1152 (2011).

26. Batstone, D. J. et al. Towards a generalized physicochemical framework. Water Sci. Technol. 66, 1147-1161 (2012).

27. Vaneeckhaute, C. et al. Development, implementation, and validation of a generic nutrient recovery model (NRM) library. Environ. Mod. Softw. 99, 170-209 (2018).

28. Flores-Alsina, X. et al. Modelling phosphorus (P), sulfur ( $\mathrm{S}$ ) and iron (Fe) interactions for dynamic simulations of anaerobic digestion processes. Water Res. 95, 370-382 (2016).

29. Lizarralde, I. et al. A new general methodology for incorporating physicochemical transformations into multi-phase wastewater treatment process models. Water Res. 74, 239-256 (2015).

30. Mbamba, C. K., Flores-Alsina, X., Batstone, D. J. \& Tait, S. Validation of a plant-wide phosphorus modelling approach with minerals precipitation in a full-scale WWTP. Water Res. 100, 169-183 (2016).

31. Solon, K. et al. Plant-wide modelling of phosphorus transformations in wastewater treatment systems: impacts of control and operational strategies. Water Res. 113, 77-110 (2017).

(i) Open Access This article is licensed under a Creative Commons Attribution 4.0 International License, which permits use, sharing, adaptation, distribution and reproduction in any medium or format, as long as you give appropriate credit to the original author(s) and the source, provide a link to the Creative Commons license, and indicate if changes were made. The images or other third party material in this article are included in the article's Creative Commons license, unless indicated otherwise in a credit line to the material. If material is not included in the article's Creative Commons license and your intended use is not permitted by statutory regulation or exceeds the permitted use, you will need to obtain permission directly from the copyright holder. To view a copy of this license, visit http://creativecommons. org/licenses/by/4.0/.

(c) The Author(s) 2019 